\title{
NESTED PCR BASED DIAGNOSIS OF TRICHURIASIS AND APPRAISAL OF PRIMER SENSITIVITY AND SPECIFICITY FOR RELIABLE DETECTION IN CLINICAL SAMPLES
}

\author{
Nath J1, 2, Roy $M^{1}$ and Singha $B^{1 *}$ \\ ${ }^{1}$ Department of Zoology, Gurucharan College, Silchar, Assam, India \\ ${ }^{2}$ Department of Biotechnology, Assam University, Silchar, Assam, India \\ DOI: http://dx.doi.org/10.24327/ijrsr.2017.0803.0080
}

\section{ARTICLE INFO \\ Article History: \\ Received $17^{\text {th }}$ December, 2016 Received in revised form $21^{\text {th }}$ January, 2017 \\ Accepted $28^{\text {th }}$ February, 2017 \\ Published online $28^{\text {th }}$ March, 2017}

\section{Key Words:}

T. trichiura, microscopy, nested PCR, school-age children, sensitivity, specificity

\begin{abstract}
Background: Reliable and sensitive diagnostic tests have important implications; otherwise it limits the understanding of disease magnitude and epidemiology. The primate whipworm Trichuris trichiura, a soil-transmitted helminth (STH) is the principal whipworm in the genus Trichuris infecting human.
\end{abstract}

Methodology and Principal Findings: In this study, we examined fecal samples from 337 schoolage children $(\geq 15)$ of Southern Assam, India for Trichuris infection using microscopy followed by species discrimination using species specific nested PCR assay and bi-directional Sanger DNA sequencing of the diagnostic fragment. We further evaluated the sensitivity and specificity of primer pairs specific for Enterocytozoon bieneusi and Cyclospora cayetanensis. Based on single fecal examination 49 were microscopically positive for characteristic Trichuris eggs with a mean length and width of $54.3( \pm 2.8) \quad \mathrm{m}$ and $23.8( \pm 1.9) \quad \mathrm{m}$ respectively, while species specific PCR assay classified that all the 49 microscopy positive samples were T. trichiura. In addition, PCR assay classified 9 more positive cases of T. trichiura infection with an overall prevalence rate of $17.2 \%$ (58/337; 95\% CI: 13.4-21.8\%). Sensitivity and specificity evaluation of the primer pairs specific for E. bieneusi and $C$. cayetanensis showed no cross-amplification with the common pathogenic gastrointestinal protozoan, bacterial DNA and were able to detect $20 \mathrm{ng}$ and $30 \mathrm{ng}$ of DNA respectively

Conclusions: The findings of our study suggest that the newer molecular diagnostic methods, particularly species specific PCR assay intensifies the detection of Trichuris infection at species level and thus help to figure out the burden of zoonotic species and its transmission in a particular geographical area. In addition, the minimum detection levels of the primer sets suggest that the designed primers are sensitive enough for accurate detection of the two emerging protozoan parasites in clinical samples with low DNA yield.

Copyright (C) Nath J et al, 2017, this is an open-access article distributed under the terms of the Creative Commons Attribution License, which permits unrestricted use, distribution and reproduction in any medium, provided the original work is properly cited.

\section{INTRODUCTION}

Trichuriasis has been increasingly recognized as an important public health concern among the soil-transmitted helminth (STH) infections worldwide with highest prevalence in Central Africa, Southern India, and Southeast Asia (Areekul et al. 2010). Among the three zoonotic Trichuris species T. trichiura is considered as the predominant one with an estimate of 600 million infections worldwide, including 114 million preschoolage children and 233 million school-age children (Stephenson et al. 2000; Ghai et al. 2014).

At the level community magnitude of prevalence frequently exceed $30-40 \%$ and even $80 \%$ in age-groups like school-age children and preschool-age children, particularly in developing countries with limited educational opportunities, substandard public sanitation, living conditions and where malnutrition, anaemias are common. The clinical manifestation associated with high intensity $T$. trichiura infection includes chronic dysentery, malnutrition rectal prolapse, anaemia, growth retardation, and clubbing of the fingers constitutes an important public health problem (Stephenson et al. 2000; Gyorkos et al. 2012).

Reliable, sensitive and affordable diagnostic tests for neglected tropical diseases are essential not only for rapid treatment decision and point of care, but also for a better understanding of the disease epidemiology in the human population. Due to intra- and inter-sample variation in egg counts, microscopic 
diagnosis can have differing sensitivities, particularly in low intensity infections (Booth et al. 2003; Krauth et al. 2012). Although definite diagnosis of trichuriasis relies on identification of characteristic egg, presence of overlapping length between eggs of these nematodes could mislead diagnosis of Trichuris species based on egg dimension alone. In addition, sensitivity of microscopic examination is further scale down as anti-helminth drug albendazole has a massive effect in passage of reduced egg besides showing low curability (Bennet and Guyatt, 2000; Vercruysse et al. 2011). Molecular based assays having high sensitivity and specificity, such as polymerase chain reaction (PCR) targeting the signature genomic location is increasingly used in determining the true magnitude of the infecting parasite.

Being an endemic area, there are limited data on the prevalence of soil transmitted helminth infection from the North Eastern part of India. Therefore, we sought to determine the true prevalence of human soil-transmitted helminth (STH) $T$. trichiura associated infection among school-age children of Southern Assam, India using nested PCR. We also aimed to evaluate the sensitivity and specificity of the primers developed in our previous study for detection of E. bieneusi and $C$. cayetanensis in clinical samples.

\section{MATERIALS AND METHODS}

Study population and sample collection: Following a crosssectional study design, a total of 337 fecal samples were collected indiscriminately from children aged $15 \mathrm{yr}$ and below, irrespective of their sex and symptom through survey work at the levels of hospitals and community of Southern Assam, India. Prior to the commencement of the study, the study design employed here was reviewed and approved by the Institutional Ethical Committee (IEC) Gurucharan College, Silchar, Assam and Assam University, Silchar (IEC/AUS/ 2013-006).

Microscopy: Within a maximum of three hours following collection, fresh fecal samples collected in wide mouth screwcapped containers, were aliquoted into two parts: one part was immediately used for microscopic analysis by direct wet mounting with Lugol's iodine (diluted 1:5 with distilled water) and the second part was stored at $-20^{\circ} \mathrm{C}$ for extraction of genomic DNA and species specific PCR assay.

Extraction of genomic DNA: The genomic DNA was purified from the frozen fecal samples using Nucleo-pore ${ }^{\mathrm{TM}}$ stool DNA kit (Genetix Biotech Asia Pvt. Ltd., New Delhi, India) as per protocol provided by the supplier with some modifications. Briefly, with the addition of five freezing-thawing cycles, samples were vortexed vigorously for 5-10 minutes in lysis buffer FL containing thrashing beads (Genetix Biotech Asia Pvt. Ltd., New Delhi, India). The samples were then processed according to manufacturer's instructions except the final elution in $50 \mu 1$ of elution buffer FEB.

Nested PCR assay: The PCR assay specific for the genus Trichuris targeting SSU rRNA gene was performed using the primer set HTT18SF0: 5'- TCTTGATTCAGTGGGTAGTGG $3^{\prime}$ and HT18SR0: 5'- CTTACTGGGAATTCCTCGTTC -3'. In the secondary PCR forward primer HTT18SF: 5'AGCGCTCCGCGGAGCACCT- $3^{\prime}$ and HTV18SF: $5^{\prime}-$
CGCCCCTTGGAGCAGCA-3' were used for $T$. trichiura and T. vulpis respectively, while a conserved primer HT18SR: $5^{\prime}$ CTGTCCCAGTCACGAGAAC- $3^{\prime}$ was used for both the species as described previously (Areekul et al. 2010). Briefly, PCR amplifications were performed in a volume of $20 \mu \mathrm{l}$ with $100 \mathrm{ng}$ of sample DNA, $1 \mu \mathrm{M}$ of each primer, $1 \mathrm{X}$ PCR buffer, $2 \mathrm{mM} \mathrm{MgCl}_{2}$, 1 X BSA, $0.2 \mathrm{mM}$ dNTPs, and $1 \mathrm{U}$ of Taq DNA Polymerase (Thermo scientific, Wattham, USA) in the MJ Mini ${ }^{\mathrm{TM}}$ (Bio-Rad Laboratories, Hercules, CA) thermal cycler.

Nested PCR assays for detection of T. trichiura and T. vulpis were performed in a separate reaction using $1 \mathrm{~L}$ of product from the primary reaction as template. Both primary and secondary reactions were performed with an initial denaturing step at $94^{\circ} \mathrm{C}$ for 90 seconds, followed by 30 cycles of $94^{\circ} \mathrm{C}$ for $30 \mathrm{~s}$ (denaturation), $62^{\circ} \mathrm{C}$ for $30 \mathrm{~s}$ (annealing), $72^{\circ} \mathrm{C}$ (extension) for $60 \mathrm{~s}$ and a final extension for $7 \mathrm{~min}$ at $72^{\circ} \mathrm{C}$. Amplicons from PCR were confirmed by their expected amplicon sizes in gel electrophoresis.

The specificity of the primer sets specific for E. bieneusi and $C$. cayetanensis designed in our previous study was tested against genomic DNA of different bacterial and protozoan pathogens for cross amplification (Nath et al. 2015). Primers sensitivity was evaluated by using different known concentration from $100 \mathrm{ng}$ to $5 \mathrm{ng}$ of extracted genomic DNA as template.

DNA sequencing: Bidirectional sequencing of the diagnostic amplicon was performed in the Genome service Centre of Department of Biotechnology, Assam University for further wet lab validation of the species specific primers. Briefly, dideoxy chain-termination reaction was carried out in a $10 \mu \mathrm{l}$ reaction consisting of approximately 50ng of purified PCR product, 5 pmole of primer, $4 \mu \mathrm{l}$ of big dye terminator V3.1 (Applied Biosystem, USA) and $3 \mu \mathrm{l}$ of double distilled water. The chain termination reaction was performed under the following conditions: 20 cycles of $96^{\circ} \mathrm{C}$ for $10 \mathrm{sec}, 55^{\circ} \mathrm{C}$ for 5 sec and $60^{\circ} \mathrm{C}$ for $4 \mathrm{~min}$. The products were purified by ethanol precipitation followed by washing with $70 \%$ ethanol. Purified samples were dissolved in $10 \mu \mathrm{l}$ of Hi-Di formamide and run in an ABI 3500 Genetic analyzer (Applied Biosystems Inc., CA, USA) as per manufacturer's instructions.

\section{RESULT}

Conventional parasitologic assay: A total of 360 fecal samples were collected from school-age children. Of these, 23 were excluded from the study because of insufficient specimens. Based on single fecal examination 49 (49/337; 14.5\%; 95\% CI $=11.1-18.9 \%$ ) fecal samples were found to be microscopically positive for characteristic Trichuris eggs. The mean length and the mean width of Trichuris eggs $(n=151)$ from fecal samples of 49 infected school-age children were $54.3( \pm 2.8) \mathrm{m}$ and $23.8( \pm 1.9) \quad \mathrm{m}$ respectively (Fig. 1). Among the infected school-age children, $33(67.3 \%)$ were infected by Trichuris species only and the remaining children 16 (32.7\%) had multiple infections with common gastrointestinal protozoan parasites.

\section{Molecular assay}


Nested PCR correctly classified all the 49 microscopy confirmed samples into Trichuris species on the basis of its expected amplicon size in gel electrophoresis. confirming the possibility of negative PCR results due to PCR inhibitors, some of the random PCR negative samples were
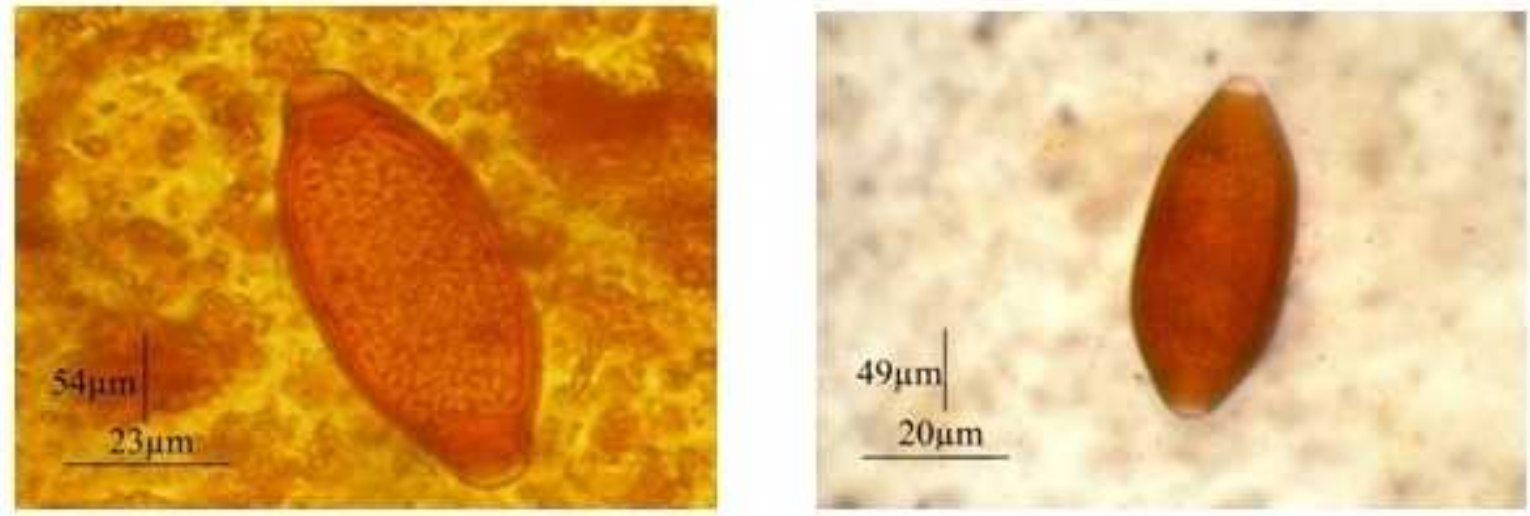

Figure 1 Representative eggs of Trichuris photographed under10×100X magnification

PCR analysis showed that all Trichuris positive specimens were $T$. trichiura showing characteristic amplicon of $212 \mathrm{bp}$ (Fig. 2). In addition, during analysis of microscopy negative samples using PCR assay, we were able to amplify the signature $T$. trichiura fragment in 9 more samples (Table 1). As per molecular consensus, the overall prevalence rate of $T$. trichiura was $17.2 \%$ (58/337; 95\% CI: $13.4-21.8 \%)$ among the school-age children of Southern Assam. To further validate the identity of the signature amplified fragment some of the positive amplicons were sequenced bi-directionally using respective primer set and deposited in GenBank with accession number (KJ188441- KJ188442).

Among female school-age children, however the overall infection rate of $T$. trichiura was somewhat higher $(9.8 \%)$ compared to male $(7.4 \%)$, although the difference was not statistically significant $(\mathrm{p}=0.272)$. In addition, we observed an age-dependency relationship with higher infection rates observed among school-age children within the age group 5-10 years.

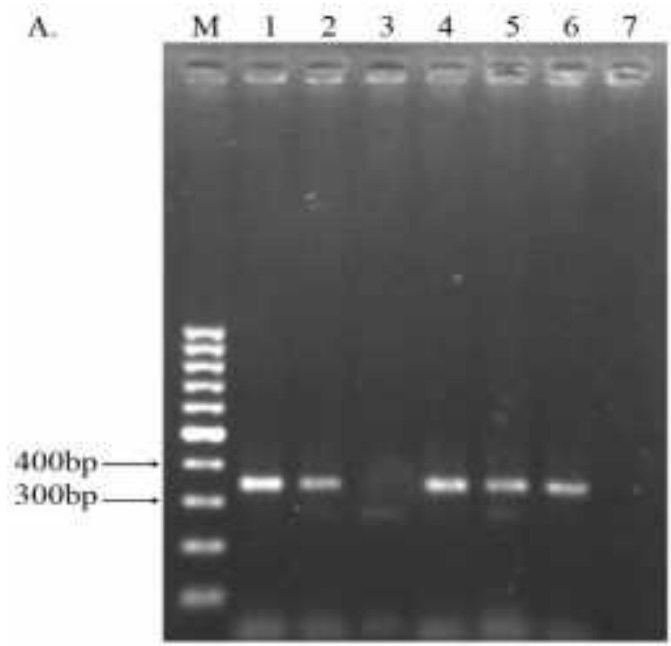

seeded with control DNA of $T$. trichiura (sequence confirmed strain). We found all the cases spiking with control DNA yielded a positive signature amplicon suggesting the absence PCR inhibitors in isolated genomic DNA.

\section{Specificity and sensitivity analysis of primer pairs}

The PCR assay employing species specific primers for $E$. bieneusi and $C$. cayetanensis designed in our previous study generate diagnostic amplicons of $596 \mathrm{bp}$ and $302 \mathrm{bp}$ respectively. No cross-amplification was observed when the primer sets specific for $E$. bieneusi and $C$. cayetanensis were tested against genomic DNA of different bacterial, helminths and protozoan pathogens like E. histolytica, E. dispar, E. moshkovskii, G. duodenalis, C. parvum, T. trichiura and E. coli (Fig 3A, B). Amplification of signature fragment from template DNA with different concentration showed that the E. bieneusi specific PCR assay was able to detect 20ng while a distinct diagnostic band was observed even when 30ng of extracted

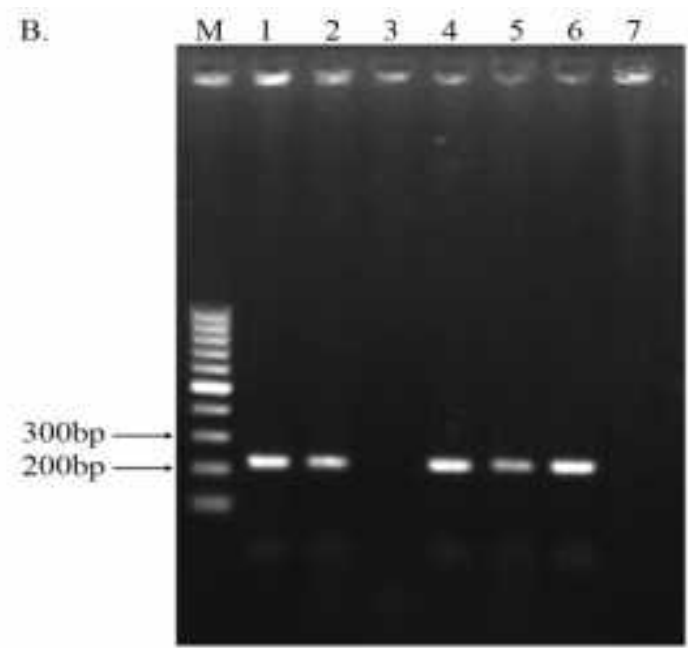

Figure 2 Nested PCR amplification using T. trichiura specific primer pair. A) PCR amplification using genus Trichuris specific primer pair. B) Secondary PCR amplification using T. trichiura using specific primer pair. Lane-M- 100bp DNA marker, lane-1- Positive control, lane-2, 4, 5, 6- Positive sample, Lane-3Negative sample, Lane-7- NTC.

Analysis of PCR inhibitor: Presence of PCR inhibitors in genomic DNA isolated from clinical specimens like fecal sample even after purification steps is a common problem which interferes with downstream analysis of the sample. For
DNA was used as template for $C$. cayetanensis diagnosis (Fig 4A, B). The minimum detection level of the two species specific PCR assays suggest that these are sensitive enough for 
accurate detection of the two species in clinical specimens with low DNA yield.
The prevalence of $T$. trichiura infection among our study participants was $14.5 \%$ as per microscopy and $17.2 \%$ as per molecular assay.
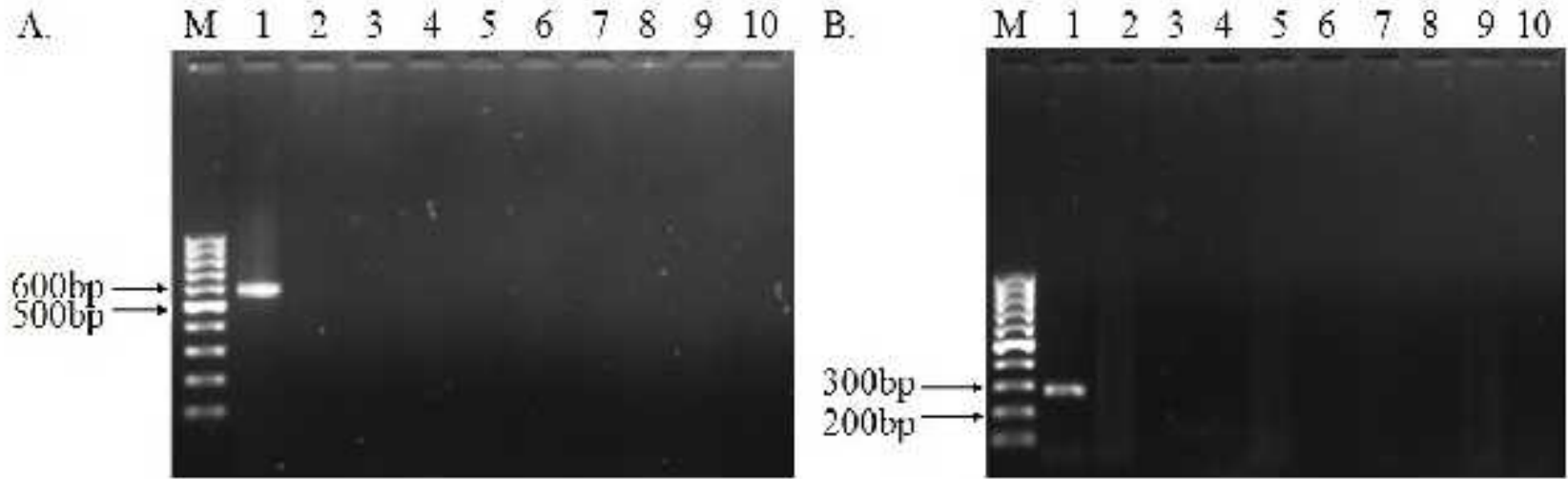

Figure 3 Specificity of primer pairs for A) E. bieneusi B) C. cayetanensis. Lane-M- 100bp DNA marker, lane-1- A) E. bieneusi and B) C. cayetanensis DNA, lane-2- E. histolytica DNA, lane-3- E. dispar DNA, lane-4- E. moshkovskii DNA, lane-5- G. duodenalis DNA, lane-6- A) C. cayetanensis and B) E. bieneusi DNA, lane-7- C. parvum DNA, lane-8- T. trichiura DNA, lane-9- E. coli (DH5 $\alpha$ ) DNA, lane-10- NTC.
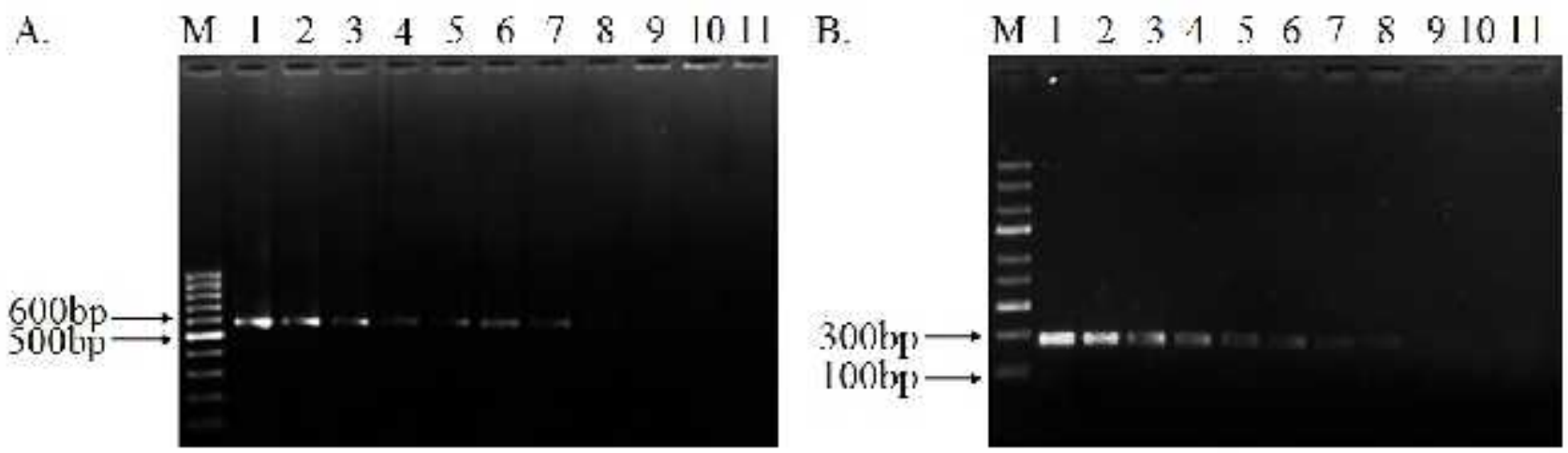

Figure 4 Sensitivity of primer pairs specific for A) E. bieneusi B) C. cayetanensis. Lane- M- A) 100bp DNA marker and B) $1 \mathrm{~Kb}$ DNA marker, lane-1- 100 ng of DNA, lane-2- $90 \mathrm{ng}$ of DNA, lane-3-80 ng of DNA, lane-4- 70 ng of DNA, lane-5- $60 \mathrm{ng}$ of DNA, lane-6- 50 ng of DNA, lane-7- 40 ng of DNA, lane-8- 30 ng of DNA, lane-9- 20 ng of DNA, lane-10-10ng of DNA, lane-11- NTC.

\section{DISCUSSION}

In general conventional microscopy based diagnosis used in clinical laboratory and epidemiological studies often under diagnosed low intensity infections as well as it fails to let identification of parasite at species level because of shared morphological features between different genus or species. The ability of PCR to specifically amplify minute amounts of pathogen DNA in low intensity infection has revolutionized the diagnosis of many infectious diseases including soil transmitted helminth infection (Nath et al. 2013; Arndt et al. 2013).

Accurate discrimination of Trichuris species has important medical and epidemiological implication in terms of its diagnosis, transmission, prevention, control and its burden. Although definite identification of $T$. trichiura in fecal specimens can be made on its characteristic egg, microscopic examination of fecal alone encounters misdiagnosis because of wide variations in egg dimension of $T$. trichiura and occurrence of overlapping dimension between Trichuris species (Yoshikawa et al. 1989; Areekul et al. 2010). In line with these findings from previous studies our study also revealed such variation in egg dimension of $T$. trichiura among school children of Southern Assam.
In addition to all microscope-positive samples PCR classified nine more samples as $T$. trichiura positive that were negative in conventional microscopy, emphasizing the importance of molecular diagnosis in a clinical setting (Ghai et al. 2014). Contrary to our findings, a much higher prevalence of $66.8 \%$ was reported from a study carried out in West Malaysia using microscopic technique (Ngui et al. 2011). A prevalence rate of $70.0 \%$ T. trichiura and $10.7 \%$ T. vulpis were observed in a rural community in northwestern Thailand using molecular technique (Areekul et al. 2010). Studies conducted across the world revealed the significance of molecular diagnosis of SoilTransmitted Helminths over microscopy methods (Basuni et al. 2011; Arndt et al. 2013).

In the present study, we did not come across any $T$. vulpis infection among the study participants. Studies from USA, Thailand and Mexico reported infection of T. vulpis in human and dogs, implying the roles of dogs in the transmission of this medically important nematode as well as its zoonotic potentiality (Dunn et al. 2002; Marquez-Navarro et al. 2012). The present study showed high prevalence of trichuriasis in the age group 10-15 yr among the school-age children. Our finding is consistent with those reported from other studies where researchers found higher prevalence in this age group (Narain 
et al. 2000; Goodman et al. 2007; Crowe et al. 2014; Kattula et al. 2014). However, Bundy et al. (1987) reported high intensity infections in the age group 2-10 yr in a St. Lucian community. In summary, our study highlighted that newer DNA based diagnostic assay like PCR intensifies the detection of Trichuris infection at species level and thus has comprehensible medical as well as epidemiological importance in terms of disease burden, zoonotic transmission, prevention and control. Absence of any canine whipworm infection minimizes the likelihood of dogs to human transmission among the study participants. The minimum detection limit of the primer sets suggests that primers designed in our previous study are specific and sensitive enough for accurate detection of the two emerging parasites $E$. bieneusi and $C$. cayetanensis in clinical samples with low DNA yield.

\section{Acknowledgements}

The authors gratefully acknowledge the Department of Biotechnology, Government of India (BT/55/NE/TBP/2010) for financial support.

\section{References}

Areekul P, Putaporntip C, Pattanawong U, Sitthicharoenchai P, Jongwutiwes S. 2010. Trichuris vulpis and T. trichiura infections among schoolchildren of a rural community in northwestern Thailand: the possible role of dogs in disease transmission. Asian Biomed. 4 (1): 49-60.

Arndt MB, John-Stewart G, Richardson BA, Singa B, van Lieshout L, Verweij JJ, Sangare LR, Mbogo LW, Naulikha JM, Walson JL. 2013. Impact of helminth diagnostic test performance on estimation of risk factors and outcomes in HIV-positive adults. PLoS One. 8(12): e81915.

Basuni M, Muhi J, Othman N, Verweij JJ, Ahmad M, Miswan N, Rahumatullah A, Aziz FA, Zainudin NS, Noordin R. 2011. A pentaplex real-time polymerase chain reaction assay for detection of four species of soil-transmitted helminths. Am J Trop Med Hyg. 84(2): 338-43.

Bennett A, Guyatt H. 2000. Reducing intestinal nematode infection: efficacy of albendazole and mebendazole. Parasitol Today. 16(2): 71-4.

Booth M, Vounatsou P, N'goran EK, Tanner M, Utzinger J. 2003. The influence of sampling effort and the performance of the Kato-Katz technique in diagnosing Schistosoma mansoni and hookworm co-infections in rural Côte d'Ivoire. Parasitol. 127(6): 525-31.

Bundy DA, Cooper ES, Thompson DE, Anderson RM, Didier JM. 1987. Age-related prevalence and intensity of Trichuris trichiura infection in a St. Lucian community. Trans R Soc Trop Med Hyg. 81(1): 85-94.

Crowe AL, Smith P, Ward L, Currie BJ, Baird R. 2014. Decreasing prevalence of Trichuris trichiura (whipworm) in the Northern Territory from 2002 to 2012. Med J Aust. 200(5): 286-9.

Dunn JJ, Columbus ST, Aldeen WE, Davis M, Carroll KC. 2002. Trichuris vulpis recovered from a patient with chronic diarrhea and five dogs. J Clin Microbiol. 40(7): 2703-4.
Ghai RR, Simons ND, Chapman CA, Omeja PA, Davies TJ, Ting N, Goldberg TL. 2014. Hidden population structure and cross-species transmission of whipworms (Trichuris sp.) in humans and non-human primates in Uganda. PLoS Negl Trop Dis. 8(10): e3256.

Goodman D, Haji HJ, Bickle QD, Stoltzfus RJ, Tielsch JM, Ramsan M, Savioli L, Albonico M. 2007. A comparison of methods for detecting the eggs of Ascaris, Trichuris, and hookworm in infant stool, and the epidemiology of infection in Zanzibari infants. Am J Trop Med Hyg. 76(4): 725-31.

Gyorkos TW, Gilbert NL, Larocque R, Casapia M, Montresor A. 2012. Re-visiting Trichuris trichiura intensity thresholds based on anemia during pregnancy. PLoS Negl Trop Dis. 6(9): e1783.

Kattula D, Sarkar R, Rao Ajjampur SS, Minz S, Levecke B, Muliyil J, Kang G. 2014. Prevalence \& risk factors for soil transmitted helminth infection among school children in south India. Indian J Med Res. 139(1): 76-82.

Krauth SJ, Coulibaly JT, Knopp S, Traore M, N'Goran EK, Utzinger J. 2012. An in-depth analysis of a piece of shit: distribution of Schistosoma mansoni and hookworm eggs in human stool. PLoS Negl Trop Dis. 6(12): e1969.

Marquez-Navarro A, Garcia-Bracamontes G, AlvarezFernandez BE, Avila-Caballero LP, Santos-Aranda I, Diaz-Chiguer DL, Sanchez-Manzano RM, RodriguezBataz E, Nogueda-Torres B. 2012. Trichuris vulpis (Froelich, 1789) infection in a child: a case report. Korean J Parasitol. 50(1): 69-71.

Narain K, Rajguru SK, Mahanta J. 2000. Prevalence of Trichuris trichiura in relation to socio-economic \& behavioural determinants of exposure to infection in rural Assam. Indian J Med Res. 112: 140-6.

Nath J, Ghosh SK, Singha B. 2013. Problem in amoebiasis diagnosis in clinical setting: a review from conventional microscopy to advanced molecular based diagnosis. J Acad Ind Res. 2(5): 257-61.

Nath J, Hussain G, Singha B, Paul J, Ghosh SK. 2015. Burden of major diarrheagenic protozoan parasitic co-infection among amoebic dysentery cases from North East India: a case report. Parasitol. 142(10): 1318-25.

Ngui R, Ishak S, Chuen CS, Mahmud R, Lim YA. 2011. Prevalence and risk factors of intestinal parasitism in rural and remote West Malaysia. PLoS Negl Trop Dis. 5(3): e974.

Stephenson LS, Holland CV, Cooper ES. 2000. The public health significance of Trichuris trichiura. Parasitol. 121: S73-95.

Vercruysse J, Albonico M, Behnke JM, Kotzed AC, Pricharde RK, McCarthyf JS, Montresorg A, Leveckea B. 2011. Is anthelmintic resistance a concern for the control of human soil-transmitted helminths? Int J Parasitol Drugs Drug Resist. 1(1): 14-27.

Yoshikawa H, Yamada M, Matsumoto Y, Yoshida Y. 1989. Variations in egg size of Trichuris trichiura. Parasitol Res. 75(8): 649-54. 